\title{
Learning with Understanding the Continuity Concept: A Teaching Experiment with Brazilian Pre-service Mathematics Teachers
}

\author{
Vilmar Gomes da Fonseca ${ }^{1^{*}}$, Ana Cláudia Correia Batalha Henriques ${ }^{2}$ \\ ${ }^{1}$ Federal Institute of Education, Science and Technology of Rio de Janeiro (IFRJ), BRAZIL \\ ${ }^{2}$ Institute of Education, University of Lisbon (IEUL), PORTUGAL \\ *CORRESPONDENCE: $\square$ vilmar.fonseca@ifrj.edu.br
}

\begin{abstract}
The literature emphasizes the interest and need to learn the concept of continuity with understanding, although this meaning it is not consensual nor specified how it may emerge and be developed in the learning process. In this paper we report the results of a study aiming to analyse Brazilian preservice mathematics teachers' understanding of the continuity of a function concept, in a context of a teaching experiment which design is based on a theoretical model for learning with understanding that consider three dimensions: the meanings of continuity concept the use of its different representations and their application in problem solving that involves it. Data collection includes participant observation with audio and video recording of the lessons, students' written and digital work on the tasks proposed during the teaching experiment, and interviews applied to the students. The qualitative and interpretative data analysis showed that students, in general, assigned different meanings to the continuity, which emerged from their concept image. At the end of the teaching experiment, they show an adequate conception of this concept, being able to articulate different representations and perform treatments and conversions to interpret and represent the (dis)continuity of a function, and to correctly apply the criteria of existence of the concept of continuity and the intermediate value theorem in the analysis of errors and in the proving of mathematical propositions, and in solving problems that call for mathematical modelling. Thus, as they revealed a learning with understanding of the continuity concept, the study also provides information to propose innovative mathematics teaching and learning methodologies aimed at improving that learning.
\end{abstract}

Keywords: continuity of functions, learning with understanding, concept meanings, representations, problem solving, pre-service mathematics teachers

\section{INTRODUCTION}

Continuity is one of the essential concepts in Calculus, a compulsory course in most undergraduate programs, because it is required for learning other advanced mathematical concepts and is the basis of several definitions and premises required for the application of its numerous theorems (Sealey, Deshler, \& Hazen, 2014). This mathematical concept is often introduced to undergraduate students when they start their university studies, particularly in the Pre-Calculus course for Brazilian pre-service mathematics teachers, as part of the mathematical knowledge they must acquire to teach mathematics (CBMS, 2012). However, previous research has shown that undergraduate students, including pre-service teachers, have difficulties in

Article History: Received 27 April $2020 \bullet$ Revised 30 June $2020 \bullet$ Accepted 4 July 2020

(C) 2020 by the authors; licensee Modestum. Open Access terms of the Creative Commons Attribution 4.0 International License (http://creativecommons.org/licenses/by/4.0/) apply. The license permits unrestricted use, distribution, and reproduction in any medium, on the condition that users give exact credit to the original author(s) and the source, provide a link to the Creative Commons license, and indicate if they made any changes. 
understanding the continuity of a function, which limits the development of other calculus concepts, and noted that the observed difficulties may be due to procedural-dominated teaching practices that neglect the development of students' conceptual understanding of mathematical content (Domingos, 2003; Sebsibe \& Feza, 2020).

Considering that the understanding in mathematics is central to students not losing their interest in the subject and to be successful in their learning, the literature emphasizes the interest and the need of learning the continuity concept with understanding, specifically using educational dynamic software, for example the GeoGebra (Dikovic 2009). Therefore, it is required to investigate alternative pedagogical approaches to teaching Calculus, enabling students to overcome these commonly observed difficulties and gain better conceptual knowledge, including understanding (Sebsibe \& Feza, 2020). However, in research, there is no consensus on the meaning of mathematical understanding, nor is it specified as such idea can be used to research and design teaching and learning processes of calculus topics (Simon, 2017). Furthermore, the empirical studies focused on how the understanding of the concept of continuity may emerge and be developed in the learning process are scarce.

In this context, we assumed as relevant to carry out a teaching experiment with pre-service mathematics teachers who were attending a discipline of Pre-Calculus, aiming to promote their learning of the continuity of a function, with understanding, which design involves the use of GeoGebra and is based on three dimensions considered as reference for this learning: development of correct meanings of the mathematical concept; work with its different representations; and resolution of problems that involves it (Domingos, 2003; Karatas, Guven, \& Cekmez, 2011).

To understand the potential of the referred teaching experiment to help pre-service mathematics teachers to develop better knowledge about the continuity of a function, which could influence the way they will teach this mathematical topic (Albuquerque et al., 2006; CBMS, 2012), and the need for further adjustments in its design, the study reported in this paper aims to analyse Brazilian pre-service mathematics teachers' understanding of the continuity concept, in the context of the described teaching experiment. In particular, we seek to answer the following questions: i) What are the meanings that students attribute to the concept of continuity of a function, when explaining or interpreting the (dis)continuity of functions?; ii) How do students recognize, represent and transform the concept of continuity in different representations?; and iii) What knowledge about the concept of continuity the students mobilize to solve problems that involve it?

Thus, this study may contribute to research on pre-service teacher education, by shedding light on how to analyse pre-service teachers' understanding of mathematical concepts, based on useful elements that allow to describe how this understanding is evidenced and to assist them in developing it in order to enhance the required mathematical knowledge for teaching.

\section{LEARNING WITH UNDERSTANDING OF THE CONCEPT OF CONTINUITY OF A FUNCTION}

\section{Understanding in Mathematics Learning}

The importance of learning mathematics, with understanding, has gained overhang and growing consensus, both in curriculum documents and in mathematics education research (e.g. Domingos, 2003; Idris, 2009; NCTM, 2000; Simon, 2017). It is also emphasized in curricular guidelines for pre-service mathematics teachers' programs (Albuquerque et al., 2006; CBMS, 2012) in order to prepare teachers to promote that understanding in their practices. In these studies it is noted that mathematics understanding is not limited to a simple recall of facts and, therefore, students should develop an understanding of mathematical concepts in their learning, contrary to a common learning that is based on the acquisition of isolated skills and only later is developed the understanding of how these skills are related to the concept learned. Thus, the understanding becomes a focus of the learning process, considered a fundamental pillar in this process, and involves an integrated knowledge of relationships, meanings and different representations of a mathematical concept, as well as connections of different concepts from the same area of knowledge or from different areas, which should be developed by students from the beginning of their learning process (Domingos, 2003; Simon, 2017).

However, the term understanding in the learning of mathematics is not consensual among the members of the educational community. A definition of understanding that fits well to the objectives of this study is presented by Skemp (1976), who considers two types of understanding of mathematical concepts: instrumental 


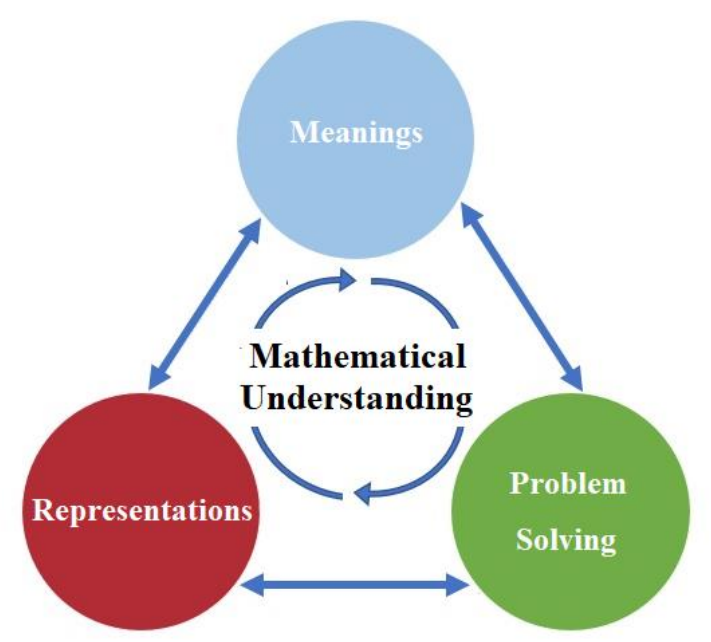

Figure 1. Model of the dimensions of mathematical understanding

understanding or relational understanding. According to the author, understanding can be instrumental, characterized by the memorization of rules or methods that allows their use in problem solving through the simple application of that knowledges. It can also be relational, which refers to knowing how and why procedures work and involves a rich and integrated conceptual structure, allowing to relate the meanings, procedures and representations, and their mobilization in problem solving. Therefore, it is this conceptual structure that allows a learning with understanding.

These two types of understanding are useful to classify the students' understanding in learning mathematics, but do not reveal which components can support us to give some information about that understanding. Therefore, we assume that the meanings attributed to the mathematical concept, the use of its different representations, and its application in problem solving involving it, are elements that allow to describe how the understanding is evidenced and developed, being considered in previous research on the learning of the concept of continuity of a function as dimensions (Figure 1) of mathematical understanding (Gutiérrez-Fallas \& Henriques, 2017; Karatas et al., 2011).

\section{The Meanings and Understanding of Continuity}

The meanings that students attribute to a mathematical concept constitute one way to express their mathematical understanding, since they reveal the students' conception of the mathematical concept (Fernández-Plaza, Rico, \& Ruiz-Hidalgo, 2013). The meanings can be evidenced from a set of verbal, graphic, symbolic or schematic responses, among others, about the mathematical concept (Gutiérrez-Fallas \& Henriques, 2017).

Often, the research on the teaching and learning of the concept of continuity of a function, is based in Tall and Vinner's (1981) theory of Concept Image and Concept Definition to explain the meanings attributed by students to this mathematical concept (e.g. Domingos, 2003; Fernández-Plaza et al., 2013; Gutiérrez-Fallas \& Henriques, 2017; Juter, 2006; Messias \& Brandember, 2015; Nair, 2010). According to Tall and Vinner (1981), the concept image describes the total cognitive structure associated with the mathematical concept, which includes all mental images, properties and processes, being built and developed through experiences of all types. Associated with this cognitive structure, the authors refer the evoked concept image as part of the concept image activated in a given context, although it do not necessarily reflect everything the student knows about the concept. The authors also define concept definition as a verbal description of the concept, which can be taught to the student or built by him, improved over time, in addition to the possibility of being different from the formal definition that is accepted by the mathematical community. For these authors, a concept definition may be nonexistent if it has not been formed or if it is forgotten by the student. If it exists, it can be inactive, as is the case for students who memorize certain definitions of mathematical concepts.

The meanings can be correct, characterized by correct concept images and appropriate to the situation under study. Consequently, they reveal the correct meaning that is attributed to the mathematical concept, 
for example, the meaning of a continuous function as a result of the equality $\lim _{x \rightarrow x_{0}} f(x)=f\left(x_{0}\right)$, characterized by correct concept images of the concept of continuity of a function based on the verification of three criteria of its existence, namely: i) $\exists \lim _{x \rightarrow x_{0}} f(x)$; ii) $\exists f\left(x_{0}\right)$; and iii) $\lim _{x \rightarrow x_{0}} f(x)=f\left(x_{0}\right)$ (Sealey et al., 2014). The meanings can also be nonexistent or conflicting when concept images are evoked by students in disconnection with the concept definition creating a cognitive conflict. Thus, misconceptions can act as an obstacle to the acquisition of new knowledge, limiting the learning of new concepts and their understanding (Tall \& Vinner, 1981). This fact is exemplified in the classic concept of continuity as the function whose graph can be drawn with the pencil without lifting it, which can lead to inaccuracies in the analysis of rational functions, which are continuous throughout the domain, but with interruption in its graph (Juter, 2006).

Therefore, the importance of actively involving students in building correct meanings of the concept of continuity, during their learning, is widely recognized. By adopting this practice it will provide opportunities for students to develop more complete meanings of the intuitive notions and the algebraic and formal notations of this concept, getting an adequate understanding of it (Gutiérrez-Fallas \& Henriques, 2017; Karatas et al., 2011; Nair, 2010; Sealey et al., 2014; Tall \& Vinner, 1981).

\section{The Representations and Understanding of Continuity}

Understanding a mathematical concept implies not only knowledge of its different meanings, but also of its multiple representations (Domingos, 2003). Since communication in mathematics is established based on representations (Duval, 2006), they are referred as fundamental for the students' learning of mathematical concepts, existing a relationship between their understanding and the representations they use (Juter, 2006).

The use of different representations of a mathematical concept helps students to get a more complete idea of it, and is a powerful resource that can assist them in solving mathematical problems (Duval, 2006). Thus, understanding a concept requires a teaching approach that addresses this diversity (Karatas et al., 2011). The ability to recognize, represent and translate the concept of continuity in its different representations is considered a requirement for its understanding, being the most considered in the teaching of this mathematical concept the verbal, algebraic, geometric and numerical representations (Karatas et al., 2011; Sealey et al., 2014).

The verbal representation of the concept of continuity consists in describing aspects of this mathematical concept using colloquial or natural language, being very common the use of intuitive notions such as 'there is no graphical interruption' and 'defined at all your points' to communicate about the continuity of a function (Karatas et al., 2011). This verbal representation is important to explain the symbologies that translate the concept and are often used by students in their written justifications when solving tasks (Sealey et al., 2014). The algebraic representations of a concept consider mathematical expressions that use algebraic symbols. Associated with the concept of continuity, they include, for example, the algebraic expression of the formal definition of continuity based on the notion of neighborhoods, or even the informal definition of continuity expressed by $\lim _{x \rightarrow x_{0}} f(x)=f\left(x_{0}\right)$. These representations are essential in solving tasks in which the validation of the (dis)continuity of a function is required (Nair, 2010). The geometric representations of the concept of continuity are commonly described by geometric records of function graphs, supported by a cartesian coordinate system, containing a register indicating the limit variables $\left(x \rightarrow x_{0} / f(x) \rightarrow f\left(x_{0}\right)\right)$ through arrows or open intervals to represent the equality $\lim _{x \rightarrow x_{0}} f(x)=f\left(x_{0}\right)$ and to justify the continuity of functions (Karatas et al., 2011). Some authors also mention the use of numerical representations associated to the concept of continuity, characterized by numerical records of ordered pairs $(x, f(x))$ of the cartesian plane, sometimes supported by tables, as a way of representing the set of points of a function $f$ (Domingos, 2003).

The use of different representations of a mathematical concept requires transforming them. For Duval (2006), these transformations can occur in two different ways, that is, through treatment and conversion. The treatments are transformations of the representations that happen within the same register, such as the algebraic calculation of $\lim _{x \rightarrow x_{0}} f(x)=f\left(x_{0}\right)$ to validate the (dis)continuity of a function $f$ at point $x=x_{0}$, which is a form of treatment of algebraic expressions (Juter, 2006). The Conversions are transformations carried out between different registers of representations, attached to one same object, such as, for example, the transformation of the algebraic expression of a function in its geometric representation (Duval, 2006). The author also highlights the importance of students being able to work fluently within and between different register of representations, in order to achieve understanding in the learning of mathematical concepts. 
The potential of using different representations of the concept of continuity for its understanding is highlighted, for example, in the studies of Tall (1993), Domingos (2003) and Sealey et al. (2014). Tall (1993), for example, focused on the results of international studies about the teaching and learning of the continuity concept, concluded that the students who achieved greater success in the learning of this concept were able to recognize and transform the different representations (algebraic, numerical and geometric), knowing operate them. Domingos (2003) shows that a student who is able to operate and establish connections between different representations of the formal definition of the $\lim _{x \rightarrow x_{0}} f(x)=f\left(x_{0}\right)$, explaining the meaning of the symbologies $\left|x-x_{0}\right|<\delta$ and $\left|f(x)-f\left(x_{0}\right)\right|<\varepsilon$ in terms of neighborhoods $V_{\delta}\left(x_{0}\right)$ and $V_{\varepsilon}\left(f\left(x_{0}\right)\right)$, recognizing the role of quantifiers in these registers and designing the $\lim _{x \rightarrow x_{0}} f(x)=f\left(x_{0}\right)$ as a result of the implication $x \in$ $V_{\delta}\left(x_{0}\right) \Rightarrow f(x) \in V_{\varepsilon}\left(f\left(x_{0}\right)\right)$, evidences to have an adequate conception of the formal definition of continuity of a function. Sealey et al. (2014) also observed that the verbalization, the writing, and the geometric register of the intermediate value theorem (IVT) proved to be fundamental to an adequate students' understanding of this theorem associated with the concept of continuity. The connections between these registers provided them multiple contexts in which they could build adequate intuitions of this theorem, which favored the meaning of algebraic notation and its role in the mathematical proposition that defines it.

All these authors emphasize that the understanding of the concept of continuity is enriched and promoted by the integrated use of its different representations, and thus suggest considering this use in the design of instructional activities for the teaching and learning of this mathematical concept, enabling students to achieve an understanding of the concept.

\section{Problem Solving and Understanding of Continuity}

Mathematical problem solving involves creative activity of experimentation, formulation of conjectures, testing and validation of them, argumentation, proof and refutation (Domingos, 2003). However, is commonly observed that students have many difficulties in solving mathematical tasks that require the application of mathematical definitions and theorems, such as the statement of mathematical propositions, for which its memorization is not sufficient (Ko \& Knuth, 2009).

The understanding the concept of continuity is linked to the ability to mobilize knowledge to solve problems that involve it (Karatas et al., 2011). In this sense, it is a common practice to use problems that request analysis of errors and mathematical proof, as well as those that appeal to mathematical modelling, both for the promotion and for the consolidation of learning about this mathematical concept (Domingos, 2003; Ko \& Knuth, 2009). The problems involving analysis of errors require the identification of errors in mathematical expressions or solving procedures and their justified correction. Sometimes, the students resort to a counterexample to refute them, being important to reinforce the meanings and fundamentals of contents that are being used in the analysis (Ko \& Knuth, 2009). The problems involving mathematical proof consist in proving mathematical conjectures, through logical and formal arguments, based on axioms, definitions or propositions, which is developed starting from logical steps to deduce the truth of the conjecture (Tall, 2006). Together, these types of problems play an important didactic role in providing students with insights into the meanings of statements (Ko \& Knuth, 2009). In addition, they constitute an opportunity for students to develop the ability to reason abstractly about definitions and theorems associated with the concept of continuity, and are often used to lead them to the formalization of this mathematical concept (Swinyard \& Larsen, 2012).

The problems that appeal to mathematical modelling involve situations in semi-real or real contexts and require the creation of a mathematical model to translate these situations (Domingos, 2003). These problems bring great interest to mathematics education as they often involve practical situations from everyday life. They can also provide an opportunity for students to develop algebraic skills in validating continuity of functions (Juter, 2006). A problem of ensuring the existence of an equation root, which is the basis of many physics and chemistry problems and requires the application of IVT, fits in this type of problems (Strand, 2016). Thus, the problems that appeal to error analysis, mathematical proof and mathematical modelling, involving the concept of continuity, constitute elements that enable students to mobilize their informal and formal knowledge about this concept, and reveal their mathematical understanding about it.

\section{PREVIOUS STUDIES ON THE LEARNING OF CONTINUITY CONCEPT}

Previous research on the learning of continuity concept highlight the importance of developing students' conceptual understanding of the intuitive notions, algebraic calculus and formal approaches associated to 
continuous functions. The intuitive notions of this concept are characterized by a correct informal mathematical knowledge based on pre-concepts, visual perceptions or unquantified actions about this concept (Tall, 2006). The knowledge of intuitive notions, designated by intuitive conception, is fundamental for the construction of the concept of continuity as it facilitates both the conception of this concept and the development of other aspects associated with it (Domingos, 2003). As an example, we have the notions of simultaneous approaches of $x \rightarrow x_{0}$ and $f(x) \rightarrow f\left(x_{0}\right)$ to describe $\lim _{x \rightarrow x_{0}} f(x)=f\left(x_{0}\right)$, and the knowledge of the uninterrupted characteristic of the graphical behavior of some continuous functions, which can favour the recognition of the (dis)continuity of a function at a point $x=x_{0}$ or in an interval (Dikovic, 2009; Juter, 2006).

The algebraic calculus associated to the continuity concept consists in the algebraic treatment of the $\lim _{x \rightarrow x_{0}} f(x)=f\left(x_{0}\right)$, which is essential to the algebraic application of the concept, as well as to validate the continuity of a function as a required condition to apply diverse calculus theorems, for example the IVT (Strand, 2016). For that, a good mastery of Algebra is required in working with variables in the manipulation and simplification of algebraic expressions and in solving limit indeterminate forms, among others, which would not be possible using only intuitive notions (Nair, 2010).

The formal approaches to the continuity concept are based on the algebraic expression of its formal definition, $\lim _{x \rightarrow x_{0}} f(x)=f\left(x_{0}\right) \Leftrightarrow \forall \varepsilon>0, \exists \delta>0$ such that if $x \in D_{f}$ and $\left|x-x_{0}\right|<\delta$ thus $\left|f(x)-f\left(x_{0}\right)\right|<\varepsilon$, which is a basis for several proofs in Calculus (Dikovic, 2009; Swinyard \& Larsen, 2012). A proper learning of this definition is essential for students to move towards a more formal and rigorous learning of the calculus concepts, and involves, among other aspects: (i) a correct interpretation of $\left|x-x_{0}\right|<\delta$ and $\left|f(x)-f\left(x_{0}\right)\right|<\varepsilon$, and of the quantifiers and their sequence in that algebraic expression; (ii) the ability to represent the continuity of a function by its formal definition and to operate with the inequalities $\left|x-x_{0}\right|<\delta$ and $\left|f(x)-f\left(x_{0}\right)\right|<\varepsilon$, in order to find the values of $\delta$ that validate the $\left|f(x)-f\left(x_{0}\right)\right|<\varepsilon$, thus ensuring the validity of the continuity of the function (Domingos, 2003; Swinyard \& Larsen, 2012).

However, the literature has pointed out students' difficulties about the learning of the continuity concept. For example, Messias and Brandember (2015), and Sesibe and Feza (2020), highlight students' cognitive difficulties, including: misunderstandings of the term continuity; incorrect conceptions of continuous function as a function that in each point of its domain has an image associated or that the $\lim _{x \rightarrow x_{0}} f(x)$ exist, or a function whose graph has no interruptions; and misconception of the discontinuity of a function at $x=x_{0}$ implying the inexistence of $\lim _{x \rightarrow x_{0}} f(x)$. For the authors, these difficulties result from cognitive conflicts present in the students' concept image, which reveal conflicting meanings of the continuity concept. Juter (2006) and Nair (2010) point out difficulties associated with procedures in Algebra, due to weaknesses in the manipulation and simplification of algebraic expressions, in the factorization and rationalization of algebraic fractions and in solving literal inequations associated to the calculus of $\lim _{x \rightarrow x_{0}} f(x)$ to decide on the (dis)continuity of a function. According to these authors, such difficulties seem to be related to the students' tendency to memorize processes, instead of understanding them, resulting in weaknesses in the treatment and conversion of algebraic records associated with the concept of continuity of a function.

Difficulties associated with learning the formal definition of continuity of a function are also evident. There are several studies noting that students, in introductory Calculus courses, generally are not able to interpret, communicate or consistently apply the formal definition of continuity, as they do not understand or are unable to operate with the algebraic symbology of this definition (Cornu, 1991; Domingos, 2003; Swinyard \& Larsen, 2012; Tall, 2006). Some of the most common difficulties referred in these studies are: misunderstanding of the use of quantifiers $\forall \varepsilon>0$ and $\exists \delta>0$ or its sequence in the formal definition, of the implicative correspondence $x \in V_{\delta}\left(x_{0}\right) \Rightarrow f(x) \in V_{\varepsilon}(L)$, and of the meaning of algebraic inequalities $\left|x-x_{0}\right|<\delta$ and $\left|f(x)-f\left(x_{0}\right)\right|<\varepsilon$, and weakness in the geometric representation and use of the formal definition of continuity to solve problems that involve it.

Thus, taking into account the students' difficulties in learning the continuity of a function, evidenced at different school grades, the research has highlighted the importance of teaching this concept through an approach that contemplates working with intuitive notions, algebraic calculus and formal approach, in an integrated way, so that students can achieve a deeper understanding of this mathematical concept and be able to apply them in problem solving (Juter, 2006). 
Table 1. Data analysis categories and respective descriptors

\begin{tabular}{cl}
\hline Understanding the concept of continuity of a function \\
\hline Meanings & $\begin{array}{l}\text { Aspects of the evoked concept image and concept definition about the continuity of a } \\
\text { function, mobilized by students, which reveal their conception about this mathematical } \\
\text { concept. }\end{array}$ \\
\hline Representations & $\begin{array}{l}\text { Representations used by students to interpret, represent, and transform (treatments and } \\
\text { conversions) the different representations of the concept of continuity of a function. }\end{array}$ \\
\hline $\begin{array}{c}\text { Problem } \\
\text { Solving }\end{array}$ & $\begin{array}{l}\text { Knowledge mobilized by students to solve problems involving the concept of continuity of } \\
\text { a function, namely, error analysis, mathematical proofs for the validation of } \\
\text { mathematical conjectures and problems that appeal to mathematical modelling. }\end{array}$ \\
\hline
\end{tabular}

\section{METHODOLOGY}

\section{Context and Participants}

This study is part of a broader investigation (Fonseca, 2019) based on a teaching experiment (Steffe \& Thompson, 2000), carried out in a Pre-Calculus course of the $1^{\text {st }}$ year of the pre-service mathematics teachers' program in Brazil. The teaching experiment, aiming at developing the learning with understanding of the concepts of limit and continuity of a function, involved the classroom application of 17 exploratory tasks addressing these concepts and integrating the use of GeoGebra.

The participants of the study are the 16 students (12 boys and 4 girls) that were attended the Pre-Calculus course during the first semester of 2016 , and about $85 \%$ of them started the course without having any academic knowledge about the concepts of limit and continuity of functions. The researcher, first author of this paper, assumed the role of a teacher during the 66 classes (45 minutes each) of the teaching experiment. The classes followed an exploratory approach (Menezes, Canavarro \& Oliveira, 2012) whose dynamic involved four moments: teacher presentation of the task to students; students autonomous work on the task, in small groups of 2 or 3 elements, involving moments of discussion between them and between them and the teacher; a final whole class discussion, guided by the teacher, where students shared and discussed their work; and a systematization of results by the teacher.

In this paper we focus on a sequence of five exploratory tasks of the teaching experiment $\left(T_{13}, T_{14}, T_{15}, T_{16}\right.$ e $T_{17}$ ), which aimed to promote learning with understanding of the concept of continuity of a function, proposed to students after the teaching of the limit concept. This sequence was conceived to contemplate the development of intuitive notions, algebraic procedures and the formal definition of the concept of continuity, by exploring, across the sequence, the meanings of the continuity of a function, the use of different representations of the concept and problem solving involving it. Moreover, in accordance with what is referred in the literature (Domingos, 2003; Juter, 2006; Strand, 2016) as learning objectives in an introduction to Calculus course, the learning objectives regarding the concept of continuity considered in these tasks, are: i) To recognize and represent the concept of continuity of a function, both geometrically and algebraically from its formal definition; ii) To recognize the continuity as a condition of the IVT; iii) To apply the formal definition to prove the continuity of a function; iv) To apply the criteria of the concept of continuity to justify the (dis)continuity of a function; and v) To apply knowledge about IVT in solving problems.

\section{Data Collection and Analysis}

This study has a qualitative and interpretative nature (Cohen, Manion, \& Mohinson, 2007). Data collection included participant observation with audio and video recording of the taught lessons and the students' written work on the tasks as well as the digital files of their work on GeoGebra. At the end of the study, a semi-structured interview (Steffe \& Thompson, 2000) was also conducted with four students to deeper the researcher knowledge about aspects of the students' understanding about this concept.

The descriptive and interpretative data analysis, focus on students' understanding of the concept of continuity of a function, is based on three categories (Table 1), namely, meanings, representations and problem solving, which were considered from the theoretical framework as components of the understanding.

In the next section, we present the results of the analysis organized by the described categories and evidenced with excerpts of students' work on the tasks (identified by $Q_{\#}$ - task question and $T_{\#}$ - task) and of the final interview (FI). To ensure the confidentiality of the data collected, the students' names are fictitious. 


\begin{tabular}{|c|c|}
\hline Graph of function $f_{1}$ & Graph of function $f_{2}$ \\
\hline $\begin{array}{c}\text { "It is not continuous. Because the graph is } \\
\text { interrupted when } x=1 \text {, that is, the graph is not } \\
\text { defined on it." } \\
\text { (Ismael and Jorge) }\end{array}$ & $\begin{array}{c}\text { "It is continuous, because there is } f(x) \text { for all values } \\
\text { assigned to } x \text {, even if the function jumps." } \\
\text { (Gil and Maria) }\end{array}$ \\
\hline
\end{tabular}

Figure 2. Answers of the pairs Ismael and Jorge, and Gil and Maria to $Q_{3} T_{13}$

\section{RESULTS \\ Meanings of Continuity}

The meanings that students attributed to the concept of continuity were evidenced in their work on solving the questions in which they were asked to decide and justify the continuity of functions graphically represented $\left(Q_{3} T_{13}, Q_{4} T_{14}\right)$ and to interpret the algebraic expression of the formal definition of the concept $\left(Q_{3} T_{15}, Q_{4} T_{15}\right)$.

When the students started the study of the continuity of a function, by solving the task $T_{13}$ in which they are asked to analyse the graph of four functions and decide on its continuity in a justified way, they assigned to the continuous function the meaning of a function whose graph has no interruptions or that each point of its domain has an associated image. These meanings reveal an intuitive conception of the continuity concept, as a result of their previous experience in the study of functions, leading them to misinterpret the graphs of functions in which the image $f\left(x_{0}\right)$ was not defined, the $\lim _{x \rightarrow x_{0}} f(x)$ did not exist or the equality $\lim _{x \rightarrow x_{0}} f(x)=$ $f\left(x_{0}\right)$ did not occur, preventing them from recognizing the (dis)continuity of these functions, as it is observed in the answers of the pairs Ismael and Jorge, and Gil and Maria (Figure 2) to $Q_{3} T_{13}$.

The answer of Ismael and Jorge, justifying the non-continuity "because the graph is interrupted when $x=$ 1 ", reveals that the students interpreted the graph of the function $f_{1}$ from the characteristic of the graph that shows an interruption, incorrectly concluding that $f_{1}$ is not continuous, not recognizing that if $x=1$ does not belong to the function domain it should not be considered in the analysis of continuity. In turn, Gil and Maria's answer, "because there is $f(x)$ for all values assigned to $x$ ", reveals their conception that the continuity of a function only requires that all values of $x$ have an image on the graph, leading them to incorrectly assume that the function $f_{2}$ is continuous even when the graph presents a jump at $x=1$, corresponding to a discontinuity point.

At the end of this task, the teacher synthesizes the criteria for continuity of a function at a point $x_{0}$, namely, i) $\exists f\left(x_{0}\right)$; ii) $\exists \lim _{x \rightarrow x_{0}} f(x)$; and iii) $\lim _{x \rightarrow x_{0}} f(x)=f\left(x_{0}\right)$. Then, in solving the task $T_{14}$, it is observed that the students' intuitive conceptions about this concept are updated to formal conceptions. For example, when answering question $Q_{4} T_{14}$, in which they must decide on the continuity of a $V$ function that models the volume of a box with a cobblestone shape, and which was represented graphically, some students use their prior knowledge of types of continuous functions to interpret continuity, associating the meaning of this concept with the preconceived continuous function. These students identified that the analytical expression of the $V$ function of the problem was a polynomial and, from there, they correctly concluded that the $V$ function is continuous all over its domain, as observed in the answer of the pair Elizeu and Vítor: "It is continuous because it is a polynomial". It is also observed that most students mobilized correct concept images associated with the meaning of continuity as a result of the equality $\lim _{x \rightarrow x_{0}} f(x)=f\left(x_{0}\right)$ at every point in the domain, as shown in André and Jorge's answer "Yes, because for every value of $x$ in the interval $[0,5]$ there is a limit and the function is defined in it, that is $\lim _{x \rightarrow x_{0}} V(x)=V\left(x_{0}\right)$. However, two groups of students still show difficulties in understanding this concept, since they did not present a justification for the continuity of this function by mobilizing concepts image associated with this concept meaning. 


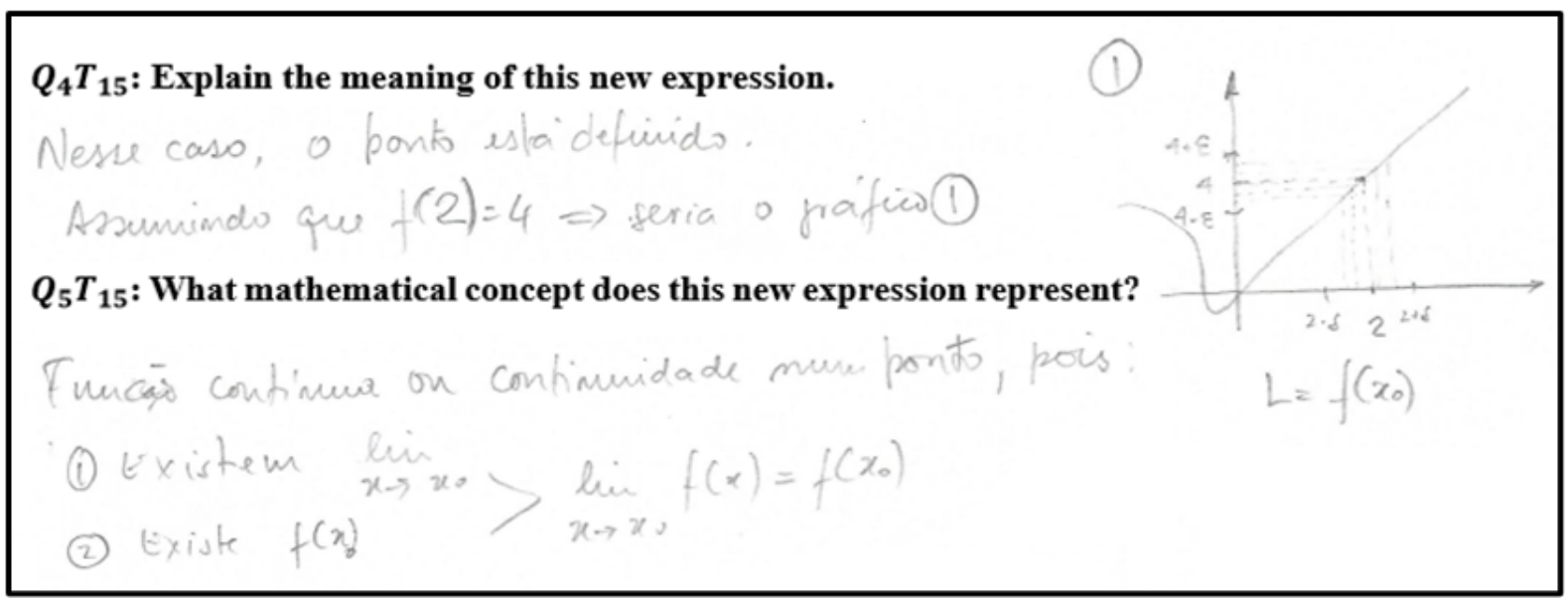

$\left[Q_{4} T_{15}\right.$ : In this case, the point is defined. Assuming that $f(2)=4 \Rightarrow$ would be the graph $1 ; Q_{5} T_{15}$ : Continuous function or continuity at a point, since: (1) there are $\lim _{x \rightarrow x_{0}}$

Figure 3. Answers of the pair Elizeu and Vítor to $\left(Q_{4}\right.$ and $\left.Q_{5}\right) T_{15}$

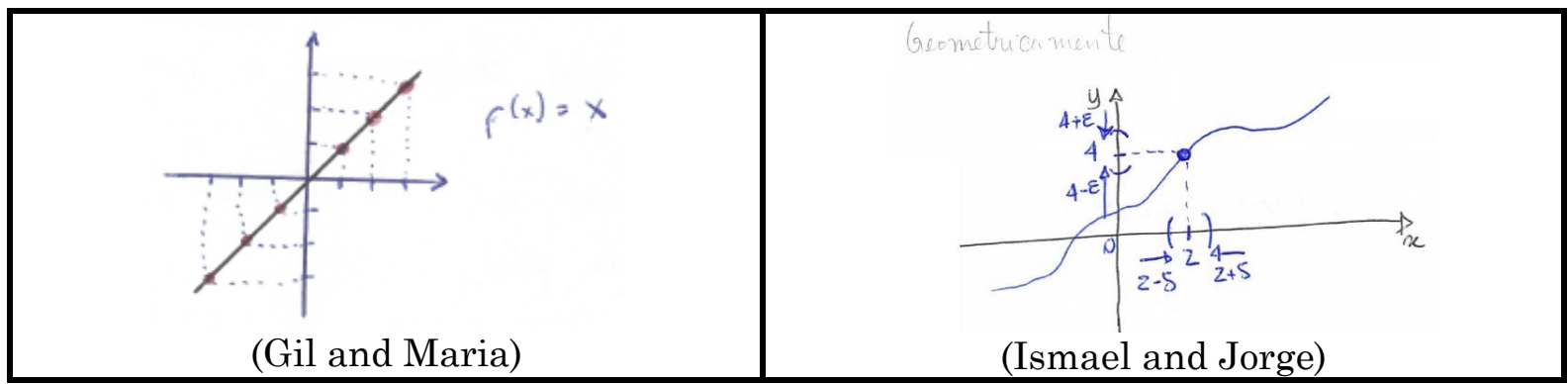

Figure 4. Students' answers to $Q_{1} T_{13}$ and $Q_{6} T_{15}$

During the didactic intervention, it was observed that the meaning of continuity associated with the equality $\lim _{x \rightarrow x_{0}} f(x)=f\left(x_{0}\right)$ was consolidated by all students in their respective concept image. The students used concept images associated with the continuity criteria of a function at a point $x_{0}$, both to interpret the concept represented by the algebraic expression of its formal definition (in $T_{15}$ ) and to justify the continuity as a condition for apply the IVT, at the end of the study (in $T_{16}$ and $T_{17}$ ). This correct conception of continuity favoured the recognition of the continuity of a function, represented by the algebraic expression of its formal definition (in $T_{15}$ ) and the (dis)continuity of a function in a closed interval $[a, b]$ represented geometrically (in $T_{16}$ and $T_{17}$ ). An example that shows this correct learning is presented in Figure 3, which contains the answers of the pair Elizeu and Vítor to $\left(Q_{4}\right.$ and $\left.Q_{5}\right) T_{15}$ in which they were asked, respectively, to explain the meaning of the expression " $\forall \varepsilon>0, \exists \delta>0$ such that if $x \in D_{f}$ and $|x-2|<\delta$ then $|f(x)-f(2)|<\varepsilon$ " and to justify the mathematical concept it represents.

These students presented correct and elucidative explanations of the $\lim _{x \rightarrow x_{0}} f(x)$ related to the value of $f\left(x_{0}\right)$, to translate the formal definition of continuity through the equality $\lim _{x \rightarrow x_{0}} f(x)=f\left(x_{0}\right)$, complementing them with algebraic register schemes and/or creating a graph of a continuous function, to justify its continuity.

\section{Representations of the Continuity Concept}

The students' ability to geometrically represent the continuity concept was analysed in the questions $Q_{1} T_{13}$ : "Draw a graph of a continuous function" and $Q_{6} T_{15}$ : "How could you represent this concept geometrically?", in which are also required transformations on the representations. It is observed that almost all students evidenced facility in creating graphic representations of a continuous function and in carrying out geometric treatments of the formal definition of continuity, some of which supported in the mathematical symbols of that definition, as exemplified by the answers of Gil and Maria to $Q_{1} T_{13}$ and of Ismael and Jorge to $Q_{6} T_{15}$, shown in Figure 4. 


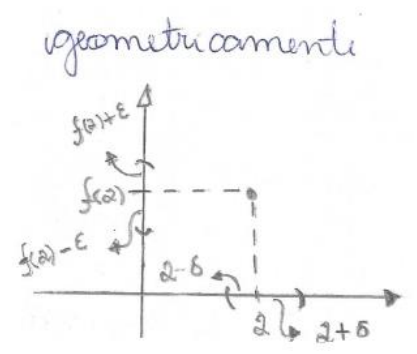

Figure 5. Answer of the pair Miguel and Paulo to $Q_{6} T_{15}$

\begin{tabular}{|l|l|}
\hline Graph of function $\boldsymbol{f}_{3}$ & Graph of function $\boldsymbol{f}_{4}$ \\
\hline $\boldsymbol{f}_{3}:$ No, since $\lim _{x \rightarrow 1^{+}} f(x) \neq \lim _{x \rightarrow 1^{-}} f(x)$. & $\boldsymbol{f}_{\mathbf{4}}:$ Yes, because $\lim _{x \rightarrow 1} f(x)=f(1)$. \\
\hline
\end{tabular}

Figure 6. Answers of Fátima and Miriam to $Q_{8} T_{13}$

Gil and Maria represented the graph of a function on the cartesian plane, registering the graphical behavior of points $(x, f(x))$ without interruptions, and Ismael and Jorge present correct geometric records of $\lim _{x \rightarrow x_{0}} f(x)=f\left(x_{0}\right)$, namely the symbology $|x-2|<\delta$ and $|f(x)-f(2)|<\varepsilon$ formed by open intervals centred on $x_{0}=2$ and $f(2)=4$, and by explanatory schemes of the point $(2, f(2))$. In this way, they show that are able to represent geometrically a continuous function and to convert the formal definition of continuity geometrically, presenting in each case a correct treatment of the converted geometric records, allowing them to present a correct geometric representation of the continuity concept. Only one pair, Miguel and Paulo, was unable to convert the formal definition of continuity into a geometric representation, as they incorrectly answered to $Q_{6} T_{15}$ (Figure 5).

This pair's answer, although presents in the cartesian plane geometric records of expressions included in the formal definition of continuity, reveals difficulties in the transformation (treatment and conversion) of the geometric representation due to the lack of the graph of the function and indications of $x \in V_{\delta}(2) \Rightarrow f(x) \in$ $V_{\varepsilon}(f(2))$.

The ability of students to recognize the continuity concept presented in different representations was analysed in questions $Q_{8} T_{13}$ and $\left(Q_{2}\right.$ and $\left.Q_{3}\right) T_{16}$, when interpreting graphs of functions to decide on the continuity of a function, and in $Q_{4} T_{15}$, in which they were challenged to interpret the algebraic expression that formally defines continuity of a function. It was observed that most students recognize the (dis)continuity of a function in the analysed graphs, having resorting in $Q_{8} T_{13}$ to the $\lim _{x \rightarrow x_{0}} f(x)=f\left(x_{0}\right)$ as an adequate and elucidative argument that correctly justifies the (dis)continuity of the functions corresponding to the graphs analysed, as exemplified in the following answers of Fátima and Miriam (Figure 6). In this way, the students show to recognize the concept of continuity, both geometrically and algebraically.

Then, in $\left(Q_{2}\right.$ and $\left.Q_{3}\right) T_{16}$, the students correctly interpret the behavior of the graph of the function $f$ at the points $x=2, a=-2$ and $b=4$, using continuity criteria, expressed in verbal or algebraic form, to assess the veracity of the equalities $\lim _{x \rightarrow 2} f(x)=f(2), \lim _{x \rightarrow a^{+}} f(x)=f(a)$ and $\lim _{x \rightarrow b^{-}} f(x)=f(b)$, which allowed them to correctly conclude that the function $f$ is continuous at the endpoints of the interval $[-2,4]$, but discontinuous in this interval, since it was not continuous in $x=2 \in[a, b]$. This conclusion is observed in the answers "No, because the lateral limits at point $x=2$ are different" and "Yes, because $\lim _{x \rightarrow-2^{+}} f(x)=f(2)$ and $\lim _{x \rightarrow 4^{-}} f(x)=$ $f(4)$ ", presented by Elizeu and Vítor, respectively, to questions $Q_{2} T_{16}$ : "This (original) function is continuous in the open interval $] a, b$ [? Justify" and $Q_{3} T_{16}$ : "Is it continuous at ends $a$ and $b$ ? Justify". 


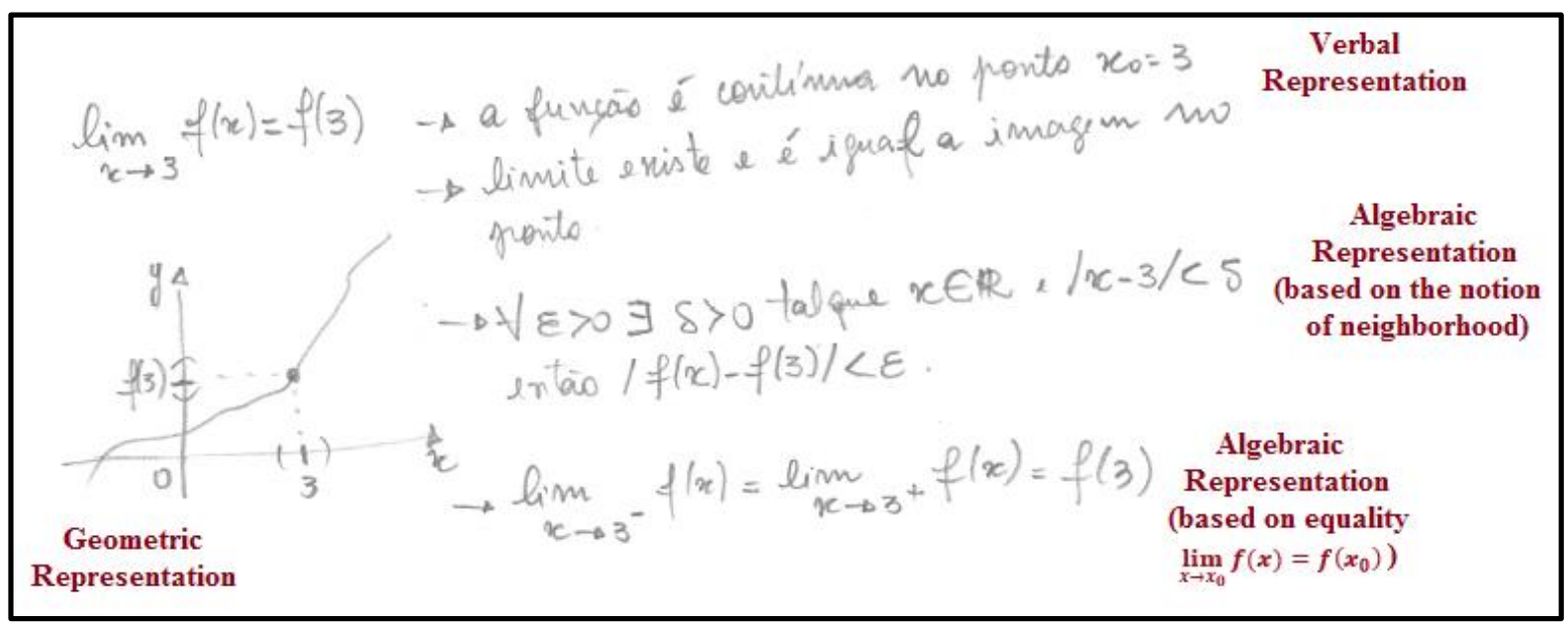

[Verbal Representation: The function is continuous at $x_{0}=3$. The limit exists and is equal to the image of the point]

Figure 7. Pedro's answer to $Q_{3} E_{F}$

Other pairs, in $Q_{8} T_{13}$ and in $\left(Q_{2}\right.$ and $\left.Q_{3}\right) T_{16}$, showed not to recognize the (dis)continuities of functions in the graphs analysed as they made mistakes in the application of the function continuity criteria, as exemplified in Ismael and Talita answer to $Q_{3} T_{16}$ : "No, the function is not continuous at points $a$ and $b$, because there is no limit and the points $x$ have images". By justifying the discontinuity of the function at points a and b stating "because there is no limit", this pair of students is using the results of calculating the lateral limits at these points, that is, $\lim _{x \rightarrow a^{-}} f(x) \neq \lim _{x \rightarrow a^{+}} f(x)$ and $\lim _{x \rightarrow b^{-}} f(x) \neq \lim _{x \rightarrow b^{+}} f(x)$, not realizing that the analysis of the continuity of the function at the interval endpoints, should consider only the analysis of its lateral limits where the function is defined, in this case, $\lim _{x \rightarrow a^{+}} f(x)$ and $\lim _{x \rightarrow b^{-}} f(x)$.

In $Q_{4} T_{15}$, all students already recognized the continuity of a function represented by its formal definition. They recognized that the expression " $\forall \varepsilon>0, \exists \delta>0$ such that $x \in D_{f}$ and $|x-2|<\delta$ then $|f(x)-f(2)|<\varepsilon$ ", corresponds to the formal definition of the limit $(L)$ at the point $x=2$, with $L=f(2)$, and that the function was defined at $x=2$, since $f(2)=4$. Thus, they correctly concluded that the algebraic expression represented the continuity of the function at $x=2$, showing a correct verbal representation of this formal definition, as shown in the answer of Cláudio and Pedro: "lim $f(x)=4=f(2)$. It is the definition of continuity in the point because the function $f$ is defined in $f(2)=4$ ".

These results evidence that, in general, students were able to make adequate and correct connections between different representations of the continuity concept, showing facility in the treatments and conversions between them. This result it is also confirmed in the students' responses to the final interview, which reveal that the criteria for the existence of continuity of functions were consolidated by the four students interviewed. When challenged in $\left(Q_{3} F I\right)$ to describe everything they know about the information $\lim _{x \rightarrow 3} f(x)=f(3)$, being $f$ a real function, all respondents recognized the continuity of $f$ at $x=3$ and justified it using the verbal representation of continuity based on the $\lim _{x \rightarrow x_{0}} f(x)=f\left(x_{0}\right)$, complementing it with algebraic and geometric representations of continuity concept, involving a correct treatment of these representations. In this way, they reveal fluency in the conversion of representations of the continuity concept, as exemplified in Pedro's answer (Figure 7).

\section{Problem Solving Involving the Continuity Concept}

With regard to problem solving, students were challenged to mobilize their knowledge of the concept of continuity in order to: (i) analyse algebraic propositions that involve the concept of continuity or IVT, proving them or justifying the inaccuracies identified in them $\left(Q_{8} T_{15}, Q_{3} T_{17}\right)$; and (ii) solve problems that appeal to mathematical modelling and involves the application of IVT $\left(Q_{7} T_{16}, Q_{1} T_{17}\right.$ and $\left.Q_{2} T_{17}\right)$.

In $Q_{8} T_{15}$, only half of the students were able to mobilize the formal definition of continuity to prove the continuity of the function $f(x)=2 x-3$ at $x=2$. The answers of these groups include a correct translation of 


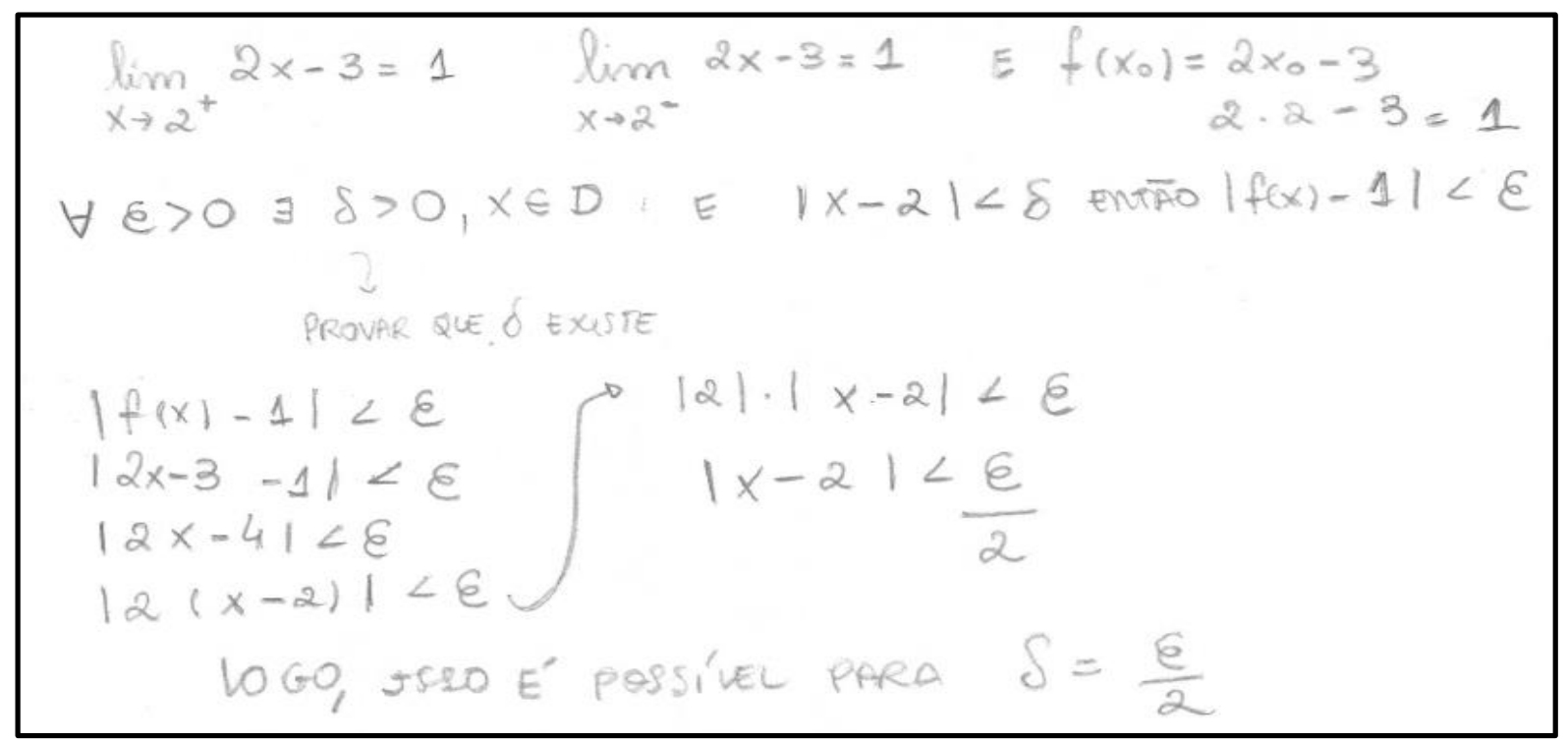

[(...) Thus, it is possible to $\left.\delta=\frac{\varepsilon}{2}\right]$

Figure 8. Answer of the pair Fátima and Miriam to $Q_{8} T_{15}$

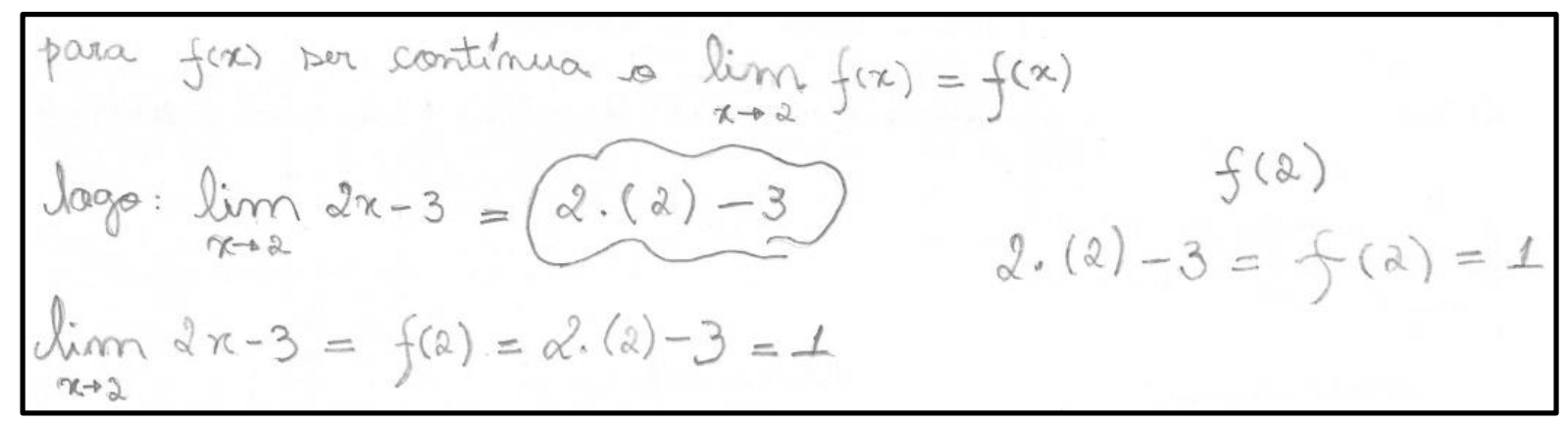

[For $f(x)$ to be continuous, the $\lim _{x \rightarrow x_{0}} f(x)=f\left(x_{0}\right)$. Thus: $\lim _{x \rightarrow 2} 2 x-3=\cdots=1$ ]

Figure 9. Answer of the pair Miguel and Paulo to $Q_{8} T_{15}$

the continuity of the function $f$ at $x=2$ from the formal definition, expressed in " $\forall \varepsilon>0, \exists \delta>0, x \in D_{f}$ and $|x-2|<\delta$ thus $|f(x)-1|<\varepsilon$ ", and a solving strategy to correctly determine the value of $\delta$ as a function of $\varepsilon$, which validates the inequalities $|x-2|<\delta$ and $|f(x)-f(2)|<\varepsilon$, as observed in the answer of Fátima and Miriam (Figure 8).

The remaining pairs of students did not applied the formal definition of continuity to prove that function $f$ is continuous at $x=2$, as exemplified in the answer of the pair Miguel and Paulo (Figure 9), in which it is observed that students resort to arguments based on the equality $\lim _{x \rightarrow x_{0}} f(x)=f\left(x_{0}\right)$ to validate the continuity, possibly due to a lack of understanding of the algebraic procedure to find a $\delta$ as a function of $\varepsilon$ that meets the formal definition.

It was also observed that almost all students, in question $Q_{3} T_{17}$, were able to correctly analyse four algebraic propositions that involve the application of IVT, proving them or justifying their inaccuracies. These students resorted to geometric records that translate the algebraic records of these propositions, analysing whether the assumptions of IVT were fullfilled in them, to prove or justify the inaccuracies. They also presented verbal explanations to complement the graphical representations of discontinuous functions used as counterexamples, as exemplified in Cláudio and Pedro's dialogue and in the graph associated with their answer to $Q_{3 . b)} T_{17}$, where they conclude: "[b) false] If $f$ is a function in which $f(1)>0>f(2)$ thus $f$ have a root in $[1,2] "$ (Figure 10). 
Pedro: item b) If $f$ is a function, it does not say that it is continuous, with $f(1)>0$. That is here [represents $(1, f(1))$ in the 1 st quadrant]. And zero is greater than $f(2)$, right?

Cláudio: Yes, this means that $f(2)$ is down there [indicates 4 th quadrant].

Pedro: So $f$ has a root in [1,2]? Yes [represents a graph containing $(1, f(1))$ and $(2, f(2)]$.

Cláudio: Why?

Pedro: Look that [Shows his graph]

Cláudio: It is continuous? You can have this here [insert an open ball at the point that crosses the $x$ axis].

Pedro: Ok. This is a counterexample.

Figure 10. Dialogue of Cláudio and Pedro and their answer to $Q_{3 . b)} T_{17}$

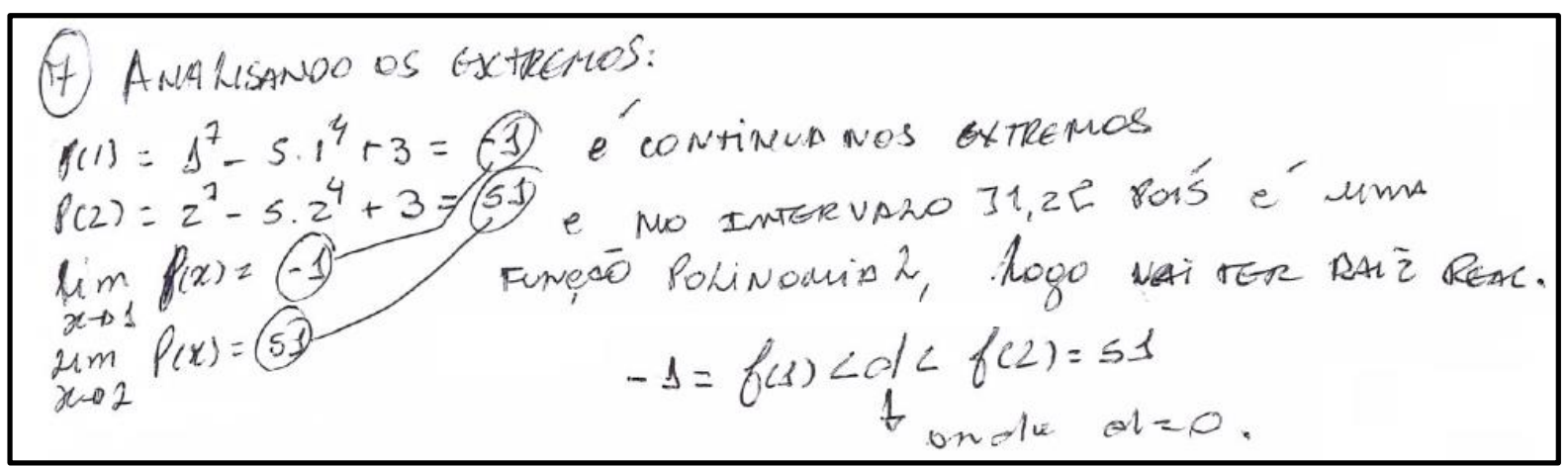

Figure 11. Answer of Talita and Joelson to $Q_{7} T_{16}$

These students analysed the hypotheses of the proposition $(f$ is a function, $f(1)>0$ and $f(2)<0)$ and identified that the continuity of the function is not guaranteed, representing in the cartesian plane the graph of a function that meets these hypotheses. Although Pedro, in the dialogue, incorrectly concluded that $f$ has a root in [1,2] and justified with the graph of a continuous function in [1,2], Cláudio corrected him justifying that the continuity of function $f$ does not be guaranteed, allowing him to consider a discontinuous function at the root point (cuts the $x$ axis) and that satisfies the conditions of the problem. Then, they identified the incorrection in the statement " $f$ has a root in $[1,2]$ ", in one of the conditions presented in item b) and present the graph of a discontinuous function as a counterexample to justify it.

Finally, all students showed facility in solving a problem that calls for mathematical modelling and requires the application of IVT when the analytical expression of the function is presented in the problem statement. As exemplified by Talita and Joelson's answer to $Q_{7} T_{16}$ (Figure 11), these students were able to recognize and prove the continuity of the function $p$ in $[1,2]$ and that que $p(1)<d<p(2)$. Based on these conditions, they concluded the existence of $x_{0} \in[1,2]$ whose image is $p\left(x_{0}\right)=0$.

In this answer, the students correctly proved the continuity of the function $p$ in $[1,2]$, justifying that the function was continuous in ]1,2[ because it is a polynomial function, and applied correctly $\lim _{x \rightarrow x_{0}} p(x)=p\left(x_{0}\right)$ to prove the lateral continuity of the function at the endpoints $x=1$ and $x=2$. They also correctly calculated the value of $p(1)$ and $p(2)$ and confirmed that the condition $-1=p(1)<d<p(2)=51$ was true for $d=0$. From this knowledge, they correctly concluded the existence of $x_{0} \in[1,2]$ such that $p\left(x_{0}\right)=0$, stating "will have real root". In this way, they reveal ability to apply IVT assumptions to prove that $p(x)=x^{7}-5 x^{4}+3$ have at least one real root in the range [1,2], responding correctly to $Q_{7} T_{16}$.

However, when solving problems that require the application of IVT, having to obtain an analytical expression of the function that models the problem through a mathematical modelling process $\left(Q_{1} T_{17}\right.$ and $\left.Q_{2} T_{17}\right)$, most students showed little mastery in mathematical modelling and difficulties with Algebra procedures. The main difficulties were not being able to express the function that models the problem and not recognizing the assumptions of IVT in these conditions, to apply it in solving the problem. An example of these 


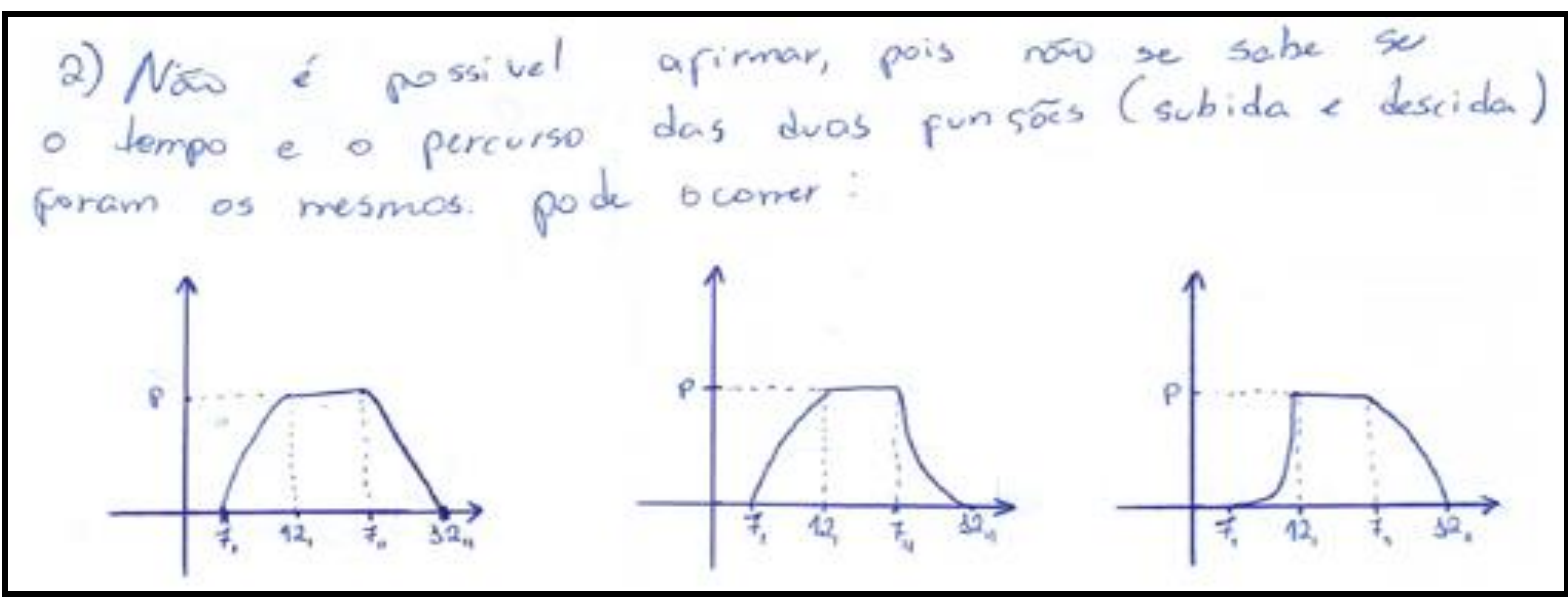

[It is not possible to state, because it is not known if the time and the route of both functions (up and down) were the same. May occur:]

Figure 12. Answer of Gil and Maria to $Q_{2} T_{17}$

difficulties are evidenced in the answer of Gil and Maria (Figure 12) to $Q_{2} T_{17}$, in which they should solve a problem that aimed to ensure the existence of a fixed point of a function $\left(x \in D_{f}\right.$ such as $\left.f(x)=x\right)$, having as a real context the climb and descent of a climber on a mountain.

In this answer, we observe that the students made an error by graphically represent the two displacements (up and down) based on a single function, and by incorrectly record their domain as an interval containing the values “ $7,12,7,, 12$, , ", instead of considering distinct continuous functions, containing the same domain [7,12] and codomain $[0, h]$. In this way, they reveal that they were not able to correctly interpret the problem, translating it into continuous functions that describe the movements of climb and descent performed by the climber in the mountain. These errors prevented them from realizing that the functions (up and down) had a common point $(x, f(x))$, which corresponded to the solution of the problem.

\section{CONCLUSIONS AND IMPLICATIONS OF THE STUDY}

In this study we analysed pre-service mathematics teachers' understanding of the continuity concept, in their learning process, based on three dimensions adopted from a theoretical framework that are considered as reference for that learning: meanings of the mathematical concept; different representations of the concept; and problem solving that involves it (Domingos, 2003; Karatas et al., 2011). The results allow to conclude that those dimensions proved to be adequate to analyse the students' understanding of this concept, during the teaching experience.

The meanings that most students attribute to a continuous function, at the beginning of their learning, as a function whose graph has no interruptions or a function that has an image associated to each point of its domain, describe intuitive conceptions of continuity resulting from their previous experience in the interpretation of graphs of functions, as observed in Juter (2006), Sealey et al. (2014) and Tall and Vinner (1981). These intuitive or limited conceptions of continuity were updated during the teaching experiment, by formal conceptions, as they started to attribute meanings to the concept associated with the existence of the limit at the point, result of equality $\lim _{x \rightarrow x_{0}} f(x)=f\left(x_{0}\right)$, or preconceived continuous functions, and did not become an obstacle to students' learning about this concept, contrary to what was observed in other studies (e.g. Cornu, 1991; Juter, 2006; Nair, 2010). In fact, the diverse correct meanings that most students attributed to continuity, which emerge from their evoked concept-image and concept-definition (Tall \& Vinner, 1981), evidence an adequate students' conception of this concept and necessary for their understanding, as pointed out by Domingos (2003) and Fernández-Plaza et al. (2013). Their adequate conceptions were then mobilized, leading them to correct conclude and justify about the continuity of a function in the proposed tasks and also to clarify the connection between its informal and formal definition, observed when they presented correct and clear explanations based on intuitive notions to conclude about the formal definition of this concept, and used correct explanations based on formal notions to define it. 
In working with different representations of the concept of continuity, most students were able to recognize the (dis)continuity of a function represented geometrically and algebraically, with records based on the algebraic expression of its formal definition. They predominantly resort to verbal representations to adequately explain the records that translate it and complement them with adequate and clarifying schemes and/or other algebraic expressions based on the criteria for the existence of continuity. The results also show the students' ability to geometrically represent the (dis)continuity of a function, by representing graphs of preconceived continuous functions as a result of their intuitive conceptions, and performing appropriate treatments of these geometric representations supported by the symbols of the algebraic expression of the formal definition of the concept, being this ability essential to understanding this concept (Domingos, 2003; Karatas et al., 2011). It is also observed that they were able to algebraically represent the (dis)continuity of functions represented geometrically and by the algebraic expression of their formal definition, showing that they have assimilated the continuity criteria required to understand this concept (Karatas et al., 2011; Messias $\&$ Brandemberg, 2015). As students were able to articulate the different representations to interpret and represent the (dis)continuity of a function, they also showed facility in carrying out treatments and conversions between representations, which evidences their understanding (Duval, 2006).

Regarding to problem solving, most students were able to mobilize their knowledge about the continuity of a function to: (i) analyze algebraic propositions that involve this concept, proving them or justifying the inaccuracies identified in them; and (ii) apply the continuity and IVT criteria to solve problems that require mathematical modelling. The use of the formal definition to prove the continuity of a function at a point proved to be a difficulty for some students, who resorted to arguments based on approximations and equality $\lim _{x \rightarrow x_{0}} f(x)=f\left(x_{0}\right)$ to justify the continuity, due to the misunderstanding of the algebraic procedure to find $\delta$ as a function of $\varepsilon$ that makes the inequalities $\left|x-x_{0}\right|<\delta$ and $|f(x)-L|<\varepsilon$ true, as also identified in the studies of Domingos (2003), Juter (2006) and Swinyard and Larsen (2012). However, unlike the results of these studies, most students were able to analyze algebraic propositions that involve the concept of continuity, proving them or justifying their inaccuracies, building geometric registers that translate algebraic symbologies, and assessing whether the criteria continuity or assumptions of IVT are satisfied in them. Based on this analysis, students validate or refute the propositions, presenting verbal explanations and/or complementing them with records of graphs of function as counterexamples, which reveals the ability to connect informal and formal knowledge about the concept, essential to their understanding (Ko \& Knuth, 2009; Sealey et al., 2014; Strand, 2016). Thus, it is possible to infer that success in solving these problems is favored by the appropriate use of the different representations of the concept of continuity.

Students, in general, showed facility in applying the assumptions of IVT to solve problems involving mathematical modelling, when these are explicitly identifiable in the problem statement. However, when this explanation of the assumptions of IVT was not so evident, requiring its translation, some students showed difficulties in applying knowledge about the concept of continuity to algebraically translate the problem in the conditions of IVT and solve it, showing little mastery in modelling and difficulties in Algebra, which reveals misunderstandings about the theorem, according to Sealey et al. (2014) and Strand (2016).

These results allow us to conclude that students, in general, show a relational understanding (Skemp, 1976) of the concept of continuity of a function, at the end of the teaching experience, being able to relate different meanings and different representations of these concepts and to mobilize them in solving problems that involve them. Despite this, some students still maintain an instrumental understanding (Skemp, 1976), showing weaknesses in the construction of identifiable representations of the concept of continuity, caused by a lack of geometric, algebraic or verbal rigor in the records of these representations. They also show weaknesses in the treatments and conversions between the different representations (algebraic and geometric) of this concept, which prevented them from carrying out some translations of it, such as, for example, geometrically representing the continuity represented by the algebraic expression of its formal definition, and formally representing the continuity of a function and apply it to solve a mathematical proof problem. In addition, they have difficulties in solving problems that require the use of algebraic calculation procedures of the limit concept and in the application of the IVT when their assumptions are not explicitly identifiable in the problem statement, revealing fragility in the integration and articulation of mathematical knowledge associated with the concept of continuity.

Although the results do not allow generalizations in view of the particular characteristics of the context and participants of the study, the exploration in the classroom of the three elements of understanding that constitute the theoretical model considered in this study may enhance students' understanding of the concept of continuity. In view of these results, this model constitutes a contribution of this study to the research in 
mathematics education that propose to promote and analyse mathematical understanding, since these three elements, namely, the meanings attributed to the mathematical concept, the work with its different representations and solving problems that involve it, are essential for the learning of any mathematical concept. It should also be noted that this theoretical model does not intend to provide a universally accepted definition of mathematical understanding, but one that is adequate to the objectives of the study. However, this study is only a first step in understanding these potentialities, as the way how this understanding emerges and develops requires a deeper research of the resources and strategies that contribute to it.

\section{Disclosure statement}

No potential conflict of interest was reported by the authors.

\section{Notes on contributors}

Vilmar Gomes da Fonseca - Federal Institute of Education, Science and Technology of Rio de Janeiro (IFRJ), Brazil and Capes scholarship holder - Brazil.

Ana Cláudia Correia Batalha Henriques - Institute of Education, University of Lisbon (IEUL), Portugal.

\section{REFERENCES}

Albuquerque, C., Veloso, E., Rocha, I., Santos, L., Serrazina, L., \& Nápoles, S. (2006). A Matemática na formação inicial de professores. Lisboa: APM e SPCE.

Cohen, L., Manion, L., \& Mohinson, K. (2007). Research methods in education (6th ed.). New York, NY: Routledge. https://doi.org/10.4324/9780203029053

Conference Board of the Mathematical Sciences - CBMS (2012). The mathematical education of teachers ii. Providence, RI and Washington, DC: American Mathematical Society and Mathematical Association of America.

Cornu, B. (1991). Limits. In D. Tall (Ed.), Advanced mathematical thinking (pp. 153-166). Dordrecht, The Netherlands: Kluwer. https://doi.org/10.1007/0-306-47203-1_10

Dikovic, L. (2009). Examining continuity/discontinuity of a function by using GeoGebra. Teaching Mathematics and Computer Science, 7(2), 241-257. https://doi.org/10.5485/TMCS.2009.0235

Domingos, A. (2003). Compreensão de conceitos matemáticos avançados - A matemática no início do superior [Understanding advanced mathematical concepts - Mathematics at the beginning of the superior] (Doctoral Thesis in Education), Universidade de Lisboa, Portugal. Retrieved from http://hdl.handle.net/10362/78

Duval, R. (2006). The cognitive analysis of problems of comprehension in the learning of mathematics. Educational studies in mathematics, 61, 103-131. https://doi.org/10.1007/s10649-006-0400-z

Fernández-Plaza, J. A., Rico, L., \& Ruiz-Hidalgo, J. F. (2013). Concept of finite limit of a function at a point: Meanings and specific terms. International Journal of Mathematical Education in Science and Technology, 44(5), 699-710. https://doi.org/10.1080/0020739X.2013.805887

Fonseca, V. (2019). Aprendizagem com compreensão dos conceitos de limite e continuidade: uma experiência de ensino com recurso ao GeoGebra na formação inicial de professores de matemática, no Brasil. Tese de Doutoramento em Educação, Universidade de Lisboa, Portugal. Retrieved from http:/hdl.handle.net/10451/42789

Gutiérrez-Fallas, L., \& Henriques, A. (2017). A compreensão de alunos de $12{ }^{\circ}$ ano dos conceitos de limite e continuidade de uma função [The understanding of 12th grade students of the concepts of limit and continuity of a function]. Quadrante, 26(1), 25-49.

Idris, N. (2009). Enhancing students' understanding in calculus trough writing. International Electronic Journal of Mathematics Education, 4(1), 36-55.

Juter, K. (2006). Limits of functions - university students' concept development (PhD Thesis), Lulea University of Technology, Sweden.

Karatas, I., Guven, B., \& Cekmez, E. (2011). A cross-age study of students' understanding of limit and continuity concept. Bolema, 24(38), 245-264. 
Ko, Y., \& Knuth, E. (2009). Undergraduate mathematics majors' writing performance producing proofs and counterexamples about continuous functions. Journal of Mathematical Behavior, 28(1), 68-77. https://doi.org/10.1016/j.jmathb.2009.04.005

Menezes, L., Canavarro, A. P., \& Oliveira, H. (2012). Teacher practice in an inquiry-based mathematics classroom. Hellenic Mathematical Society-International Journal for Mathematics in Education, 14, 357362.

Messias, M. \& Brandember, J. (2015). Discussions about the relation between limit and continuity of a function: investigating concept images. Bolema, 53(29), 1224-1241. https://doi.org/10.1590/19804415v29n53a21

Nair, G. (2010). College students' concept image of asymptotes, limits and continuity of rational functions (PhD Thesis), College of Education and Human Ecology, USA.

NCTM (2000). Principles and standards for school mathematics. Reston, VA: NCTM.

Sealey, V., Deshler, J., \& Hazen, K. (2014). Strengthening student understanding of mathematical language through verbal and written representations of the intermediate value theorem. PRIMUS: Problems, Resources, and Issues in Mathematics Undergraduate Studies, 24(2), 175-190. https://doi.org/10.1080/10511970.2013.858282

Sebsibe, A. S., \& Feza, N. N. (2020). Assessment of students' conceptual knowledge in limit of functions. International Electronic Journal of Mathematics Education, 15(2), em0574. https://doi.org/10.29333/iejme/6294

Simon, M. (2017). Explicating mathematical concept and mathematical conception as theoretical constructs for mathematics education research. Educational Studies in Mathematics, 94, 117-137. https://doi.org/10.1007/s10649-016-9728-1

Skemp, R. (1976). Relational understanding and instrumental understanding. Mathematics Teaching, 77, 2026.

Steffe, L., \& Thompson, P. (2000). Teaching experiment methodology: underlying principles and essential elements. In. R. Lesh \& A. Kelly (Eds.), Research design in mathematics and science education (p. 267307). Hillsdale, NJ: Erlbaum.

Strand, S. (2016). The intermediate value theorem as a starting point for inquiry - oriented advanced calculus (PhD Thesis), Portland State University, USA. https://doi.org/10.15760/etd.2910

Swinyard, C., \& Larsen, S. (2012). Coming to understand the formal definition of limit: insights gained from engaging students in reinvention. Journal for Research in Mathematics Education, 43(4), 465-493. https://doi.org/10.5951/jresematheduc.43.4.0465

Tall, D. (1993). Students' difficulties in calculus. In Proceedings of Working Group 3 on Students' Difficulties in Calculus, ICME-7 (pp. 13-28). Québec, Canada: ICME.

Tall, D. (2006). The transition to advanced mathematical thinking: functions, limits, infinity and proof. In D.A. Grouws (Ed.), Handbook of Research in Mathematics Teaching and Learning (pp. 495-511). New York, NY: Macmillan.

Tall, D., \& Vinner, S. (1981). Concept image and concept definition in mathematics with particular reference to limits and continuity. Educational studies in Mathematics, 12(2), 151-169. https://doi.org/10.1007/BF00305619 